\title{
The Role of Agricultural Extension in Decentralizing the Sensitivity of Vegetable Farmers to the Risk of Residual Pesticide Effects
}

\author{
Aiman Hamad Eltyeb ${ }^{1 *}$, Elshifa Ali Mergani ${ }^{2}$, Omeima Bashir Khalid ${ }^{2}$, \\ Tawheed Mohammed Elheesin Shareef ${ }^{3,4}$, Khalid Ahmed Abbakar ${ }^{5,6}$
}

\author{
${ }^{1}$ Department of Economic Agricultural and Rural Development, Faculty of Agricultural and Environmental Sciences, \\ University of Gadarif, Gadarif, Sudan \\ ${ }^{2}$ Department of Agricultural Extension and Rural Development, College of Agricultural Studies, Sudan University of Science and \\ Technology, Khartoum North, Sudan \\ ${ }^{3}$ Gansu Academy of Agricultural Sciences, Lanzhou, China \\ ${ }^{4}$ Department of Agriculture Engineering, Faculty of Agriculture, University of Khartoum, Khartoum, Sudan \\ ${ }^{5}$ Department of Mathematics and Physics, Faculty of Education, University of Gadarif, Gadarif, Sudan \\ ${ }^{6}$ College of Mathematics and Statistics, Northwest Normal University, Lanzhou, China \\ Email: ^aimanhamad99@gmail.com
}

How to cite this paper: Eltyeb, A.H., Mergani, E.A., Khalid, O.B., Shareef, T.M.E. and Abbakar, K.A. (2020) The Role of Agricultural Extension in Decentralizing the Sensitivity of Vegetable Farmers to the Risk of Residual Pesticide Effects. Agricultural Sciences, 11, 722-729.

https://doi.org/10.4236/as.2020.118047

Received: April 21, 2020

Accepted: August 18, 2020

Published: August 21, 2020

Copyright $\odot 2020$ by author(s) and Scientific Research Publishing Inc. This work is licensed under the Creative Commons Attribution International License (CC BY 4.0)

http://creativecommons.org/licenses/by/4.0/

\section{cc) (i) Open Access}

\begin{abstract}
This study was carried out in the northern Khartoum (Bahry Locality) with the aim of knowing the role of agricultural extension in developing the awareness of the farmer to the danger of residual effect of pesticides (vegetable farmers). The social survey method was used to conduct this study; 100 vegetable farmers were selected randomly. The data collected through questionnaires, observation, and interviews for primary data, previously concerned, and reference documents were used to collect secondary data. Data collected were analyzed using the statistical packages for social science (SPSS). The study yielded some useful results, the most important of which are: the presence of respondents who obtain their information about pesticides from merchants, the absence of a guide provider in their area, and the absence of any seminars or lectures on the use of pesticides, or programs. For example, radio and television programs were presented but protective clothing was not used. This study is based on the researcher's advocate for the following: intensifying agricultural extension and employee visits to the agricultural field, in addition to intensifying educational evidence for consumers regarding pesticides and providing preliminary data on pesticides and how to deal with them and increase them. Educate farmers about the safe use of pesticides and identify the risks and damages that pesticides cause to humans.
\end{abstract}




\section{Keywords}

Agricultural Sector, Pesticides, Vegetables, Awareness

\section{Introduction}

Agriculture in Sudan is the main pillar of the Sudanese economy and is the main economic activity of the Sudanese countryside. Eighty percent of Sudanese depend on agriculture for their decent living. Agriculture contributes about 30 percent of the national product and about 90 percent of exports [1]. The agricultural sector consists of two main sectors, plant, and animal. Although the arable area is estimated at about 200 million acres, the area already cultivated with irrigated and rain crops does not exceed 30 million acres, but compared to the areas in many neighboring countries, is considered a vast area as in [2]. Sudan has known vegetable cultivation from a time when far away and has gained great importance recently due to awareness and its nutritional and economic value and the area cultivated with vegetables in Sudan is estimated at about 525 thousand acres as in [3].

Vegetables and fruits occupy large areas; however, growing vegetables still do not meet the requirements of the local market. The cultivation of vegetables and fruits is also one of the areas that are exposed to pesticide contamination, which is used to control insect and fungal diseases and chemical fertilizers through agricultural processes and post-harvest as in [4]. He defined chemical pesticides as chemicals that are used to control agricultural pests or any kind of organism that could constitute a pest on agricultural crops [5]. Storage operators are concerned with pollution problems for some reasons, including: 1) not knowing the groups working in the agricultural sector, especially producers and workers, the danger of pesticides and fertilizers, 2) lack of specifications that identify pesticide residues in these products, 3) lack of trained technical staff, 4) poor agricultural extension as in [6]. And that's right here the use of vegetable pesticides is a major safety problem for any farmer spraying, usually limited to the use of pesticides, the use of appropriate pesticides and appropriate doses, and it is not responsive to the extension. While acknowledging the damage caused by pesticides to the environment in general and to humans in particular, we hope to find a common formula through which they can contribute to an appropriate solution to the problem. In this way, it can be said that the existence of legislation or a system capable of reducing these damages requires research into the role that agricultural extension can play in educating farmers as well as how to rationalize the use of pesticides through the methods of work used through which the appropriate solutions to these damages lie as in [7]. Agricultural extension is one of the practical aspects that combine both guidance education and agricultural sciences, i.e. the process of selecting the appropriate agricultural techniques for 
agriculture and providing them with a simplified method through the methods and guidance tools to learn them and no one can carry out an agricultural indicative activity efficiently if he knows one side without the other. The government's work on the issue of the "family" is a very important issue. The importance of agricultural extension is highlighted as one of the specialized agricultural sciences that works to properly link the products of agricultural research represented by modern agricultural technology and areas of application in the countryside by educating farmers and convincing them of the importance of these agricultural techniques and training them in use correct and continuous to them. The agricultural extension service is influenced by the nature of the economic and social conditions for all, so we find that the form and mechanisms of this service are occupied from one country to another. The distinguished agricultural extension service is a product of sincere cooperation and efforts by officials and participants in the field of agricultural guidance and agricultural research in addition to implementation among those with field experience in dealing with farmers as well as the government and private entities concerned rural development as in [8] [9]. Results indicated that most of the $83 \%$ of the farmers surveyed resort to several sources to inquire about pesticides and their use, namely parents and acquaintances, pesticide dealers, the preamble of the pesticide, which is the most important source of information. Therefore, the main objectives of this paper are the role of agricultural extension on developing awareness of the farmer to the danger of residual effect of pesticides, knowing the extension of the method used in the development of the awareness of the farms about the danger of pesticides, and the role of extension activities in the development of farmer awareness of the danger of the residual effects of the meds on the safety and safety of the consumer.

\section{Methodology}

\subsection{Study Area}

The area of villages is located in the locality of Bahri and is bordered by the Blue Nile to the south and the border of the Nile River state in the north and the east local sea (East Nile) and the west bordered by the Nile River.

The total number of farmers (7) thousand farmers, a random stratified homogeneous stratified sample of all farmers in the villages was selected in the following table with a sample of 100 farmers:

Table 1 shows the villages and the number of farmers and researchers of the villages that were studied:

Social survey methods were used to conduct the research. The primary data have been collected through interviews, critical observation, and questionnaires. The secondary data were collected from documents, articles report, and website or internet; these secondary data are useful for purveying background information. 


\subsection{Data Analyses}

The data was entered into the computer and analyzed by the Statistical Product for Science \& Services programs (SPSS) to reach percentages and frequencies.

\section{Results and Discussions}

\subsection{Distribution of Respondents}

Level of knowledge of pesticide data sources: the data are presented in Table 2. From the table, it is clear that $69 \%$ of the researchers receive their information about pesticides from pesticide dealers and sellers, and $16 \%$ of the researchers receive from friends due to the contact of farmers with companies and traders and with each other more than the other sources due to the weakness of the extension system in the region.

\subsection{Frequency Distribution}

From Table 3, it is clear that $53 \%$ of the researchers confirmed the absence of an

Table 1. Villages and the number of farmers and researchers.

\begin{tabular}{ccc}
\hline Villages & Number of farmers & Number of researchers \\
\hline Wawissi & 3000 & 43 \\
Geely & 2520 & 36 \\
Shmbat & 1480 & 21 \\
Total & 7000 & 100 \\
\hline
\end{tabular}

Table 2. Distribution of respondents according to knowledge about sources of information on pesticides.

\begin{tabular}{ccc}
\hline Sources of information & Frequencies & $\%$ \\
\hline $\begin{array}{c}\text { Agricultural extension } \\
\text { Plant protection }\end{array}$ & 9 & 9 \\
Farmers' union & 5 & 1 \\
Friends & 1 & 16 \\
Pesticide dealers and companies & 16 & 69 \\
Research centers & 69 & -
\end{tabular}

Table 3. The frequency distribution and percentages of the researchers with an extension office in their respective regions.

\begin{tabular}{ccc}
\hline Extension office in the area & Frequencies & $\%$ \\
\hline There's an office & 47 & 47 \\
There's no office & 53 & 53 \\
Total & 100 & 100 \\
\hline
\end{tabular}


extension office in their area, and $47 \%$ of the researchers confirmed the existence of an extension office in their area despite the importance of extension in raising awareness and providing services to farmers in various fields of vegetable cultivation, especially the correct methods of using pesticides.

\subsection{Agricultural Guide}

Through Table 4 , it is clear that $81 \%$ of the researchers confirmed that the agricultural guide does not provide any assistance and does not visit them and there is no guidance program in the use of pesticides and $12 \%$ of the researchers confirmed that the agricultural guide visits and gives the necessary guidance due to their good relationship with the guide (friends).

\subsection{Distribution of Respondents}

From Table 5, it is clear that $93 \%$ of the researchers confirmed that pesticides are harmful, and this indicates their knowledge of the danger of pesticides, while $7 \%$ of the researchers confirmed that they are harmless and this indicates a lack of awareness of their seriousness and lack of guidance programs in their awareness of this. Similarly, Table 4 shows the distribution of respondents with numeric values on their knowledge of the damage of pesticides. Most of them (93\%) had a high level of knowledge. Researchers as in [10] also reported the risk of pesticides on the environment and public health in developing countries.

\subsection{Precautionary Methods}

Through Table 6 , it is clear that $88 \%$ of the researchers reported that they do not use protective clothing despite their knowledge of the danger of the pesticide, and $12 \%$ of the researchers reported that they use it and this indicates their full

Table 4. The advice provided by the agricultural guide.

\begin{tabular}{rcc}
\hline Type of assistance provided by the agricultural guide & Frequencies & $\%$ \\
\hline Who visits and gives the necessary instructions in different field & 12 & 12 \\
Explains the types and use of pesticides & 3 & 3 \\
Offers extension bulletins & 4 & 4 \\
Total & 81 & 81 \\
$\begin{array}{r}\text { Who doesn't provide any help he doesn't visit them, } \\
\text { and there's no guideline program in the use of pesticides. }\end{array}$ & 100 & 100 \\
\hline
\end{tabular}

Table 5. Distribution of respondents according to their knowledge about the damage of pesticides.

\begin{tabular}{ccc}
\hline Pesticide damage & Frequencies & $\%$ \\
\hline Yes, pesticides are harmful. & 93 & 93 \\
There's no damage to pesticides. & 7 & 7 \\
Total & 100 & 100 \\
\hline
\end{tabular}


awareness of the danger of pesticides in the absence of wearing protective clothing and therefore it is necessary to implement programs awareness in this area.

While handling pesticides, preventive measures approved by farmers are presented in Table 6. A study was conducted on 502 farms that use pesticides in Minnesota. The USA it was observed that $95 \%$ of them realized the importance of wearing protective clothing or wears; $88 \%$ knew about exposure to pesticides could cause the potential damage; $56 \%$ were wearing protective gloves for chemicals and $22 \%$ wore gloves for other farm operations and $75 \%$ of the time during the process of pesticide application.

\subsection{Distribution of Respondents According to Extension Methods}

From Table 7, it is clear that $57 \%$ of the researchers confirmed that the extension methods used in the field of pesticides are radio and television programs. This indicates that other methods are few in use due to the lack of attention of the extension system to these aspects, which help raise farmers' awareness and ownership of the skill and use of the pesticide.

\subsection{Frequency Distribution and Percentages of the Researchers}

From Table 8 , it is clear that $77 \%$ of the respondents confirmed that they had received assistance from friends and businesses in finding out the residual effect of the pesticide.

\subsection{Extension Programs}

It is clear from Table 9 that $57 \%$ of the extension programs provided to farmers about pesticides are radio or television programs, which confirms that it is one

Table 6. Precautionary methods used when dealing with pesticides.

\begin{tabular}{ccc}
\hline Use of protective clothing & Frequencies & $\%$ \\
\hline Don't use it. & 88 & 93 \\
Use it sometimes. & 12 & 7 \\
Total & 100 & 100
\end{tabular}

Table 7. Distribution of respondents according to extension methods.

\begin{tabular}{ccc}
\hline Extension methods used in the field of pesticides & Frequencies & $\%$ \\
\hline Field visits & 10 & 10 \\
Field demonstration & 5 & 5 \\
Seminar & 9 & 9 \\
Lectures & 9 & 9 \\
Radio and television & 57 & 57 \\
Extension bulletins & 10 & 10 \\
Total & 100 & 100
\end{tabular}


Table 8. Frequency distribution and percentages of the researchers by who helped them to know the residual effects of pesticides.

\begin{tabular}{ccc}
\hline Helpers to know the residual effect of pesticides & Frequencies & $\%$ \\
\hline Agricultural extension & 3 & 3 \\
Protection & 3 & 3 \\
Agricultural research & - & - \\
Farmers' union & - & - \\
Commercial companies & 38 & 38 \\
Friends & 39 & 39 \\
Total & 100 & 100 \\
\hline
\end{tabular}

Table 9. Type of extension programs implemented in the field of pesticides.

\begin{tabular}{ccc}
\hline Extension programs in the field of pesticides & Frequencies & $\%$ \\
\hline Awareness programmers & 22 & 22 \\
Training in the field of type and use of pesticides & 1 & 1 \\
Field visits & 5 & 5 \\
Radio or television programmers & 57 & 57 \\
Extension seminar & 5 & 5 \\
No & 10 & 10 \\
Total & 100 & 100 \\
\hline
\end{tabular}

of the most common types of extension activity, and the least indicative activity used is dribbled and up to $1 \%$, note that it is one of the most important types of programs. Extension can benefit the farmer and lead to an increase in his information and raise his abilities and change his behavior, which positively affects the knowledge and use of pesticides.

\section{Conclusions and Recommendations}

The study concluded that there are some problems facing pesticide users such as (health-dosing-disposal of pesticide utensils-lack of protective clothing). This could be due to the ineffectiveness of the extension system in this aspect and those who help; they know that the residual effect of the pesticide is commercials. The analysis also concluded that there is no role for agricultural extension in raising awareness and providing services to farmers in various fields of vegetable cultivation, especially the correct methods of using pesticides.

Based on the findings of the study the following recommendations are made: the study recommends the need for designing and executing extension. Programs on the proper and safe methods for pesticide handling and application are needed in the kingdom. Improvements in agricultural extension efficiency and better communication with farmers and between research centers need to be made. More emphasis should be placed on the sources that farmers rely on. Brochures and field visits as a means of sources of information have received 
more attention in the extension programs. Farmers should be enlightened on the importance of the periodic check-up of their workers especially those who are dealing with pesticides.

\section{Acknowledgements}

The authors are indebted to the college of agricultural studies, Sudan University of science and technology (SUST), for availing research facilities. Furthermore, the authors acknowledge the valuable help of the ministry of agriculture for help and advice during collection data.

\section{Conflicts of Interest}

The authors declare no conflicts of interest regarding the publication of this paper.

\section{References}

[1] Ministry of Agriculture (2010) Proper Storage of Pesticides, Advisory Bulletin, Khartoum, Sudan.

[2] Bashir, Al-T.K. (1995) Report on Sudan's Experience in the Field of Pesticide Use and Proposals to Avoid Its Dangers to Human Beings and the Environment, Khartoum, Sudan.

[3] Horticultural Department (1993-1994) Annual Performance Report. Khartoum, Sudan.

[4] Sudanese Authority for Standards, 2000 M, Saman Quality Control. University of Khartoum Press, Sudan.

[5] Al-Rawabdeh, F.A. (2019) Chemical Agricultural Pesticides. https://www.ecomena.org/chemical-pesticides-ar/

[6] Alam, Z. (1996) Pesticides Use and Handling at Farm Level in Bangladesh (1996). Grassroots, 5, 19-25.

[7] Hamid, A. and Henry, Z. (2000) Environmental Toxicity and Bio-Reactions of Chemicals and Pesticides. Arab Publishing and Distribution Publishing House, Cairo, Egypt and General Secretariat in Bruit, Lebanon.

[8] Kashata, A.H.A. (2011) Agricultural Extension Scientific Foundations and Applications. Cairo University, Faculty of Agriculture, Egypt.

[9] Aziz, A. and Hassan, K. (2017) Role of Agricultural Extension in Raising Farmers Awareness against Risks of Pesticides' Residues (Vegetable Farmers in El Saggay Alkobra).

[10] Cornwall, J.E., Ford, M.L., Liyanage, T.S. and Daw, D.W.K. (1995) Risk Assessment and Health Effects of Pesticides Used in Tobacco Farming in Malaysia. Journal of Public Health Policy and Planning, 10, 431-437. https://doi.org/10.1093/heapol/10.4.431 